\title{
Innovation and Growth: Theory
}

\author{
Omar Licandro
}

\subsection{INTRODUCTION}

This chapter surveys the literature on innovation, endogenous growth and firm dynamics, aiming to better understand the mechanisms through which innovation policies affect the progress of technology, productivity growth, output growth and welfare. When modeling the macroeconomy with the objective of evaluating the effect of innovation policies, the modeler has to fundamentally understand the different mechanisms through which a policy is expected to affect the dynamics of the economy through innovation. Since innovations fundamentally diffuse through a complex process of firm, plant and product creation and destruction, it is critical to understand the relation between innovation and the dynamics of market selection.

In writing this survey, an effort has been made to keep notation consistent across different models, imposing assumptions and interpreting results under a common framework, making models as comparable as possible. Section 3.2 gives a preliminary picture of these similarities by

\footnotetext{
O. Licandro $(\bowtie)$

University of Nottingham, Nottingham, UK

e-mail: Omar.Licandro@nottingham.ac.uk
}

(C) The Author(s) 2022

U. Akcigit et al. (eds.), Macroeconomic Modelling of ReD D

and Innovation Policies, International Economic Association Series, https://doi.org/10.1007/978-3-030-71457-4_3 
pointing out some fundamental issues that arise when modeling innovation in a context of heterogeneous firms. It stresses the dynamic nature of the innovation process, describes the usual assumptions about firm heterogeneity in the context of innovation models of perfect, monopolistic and oligopolistic competition, uses aggregation theory to relate models of heterogeneous firms with the one-final-good Neoclassical and endogenous growth models, draws attention to the equivalence between (sunk) entry costs and R\&D irreversible investments, as well as the embodied nature of technical progress.

Section 3.3 describes and analyzes firm heterogeneity in models of exogenous growth, starting with the perfectly competitive model of heterogeneous firms first developed by Hopenhayn, to then study a close economy version of the monopolistic competitive model first suggested by Melitz (2003) to finally refer to the close economy version of the oligopolistic model developed by Impullitti and Licandro (2018).

Finally, Sect. 3.4 studies firm heterogeneity in models of endogenous growth in order to understand the role of selection in shaping innovation and productivity growth. This section relates the traditional Romer (1990) and Schumpeterian (Aghion \& Howitt, 1992) models to the recent literature on endogenous growth with firm heterogeneity, discussing the selection and imitation mechanism suggested by Luttmer (2007) and Klette and Kortum (2004).

\subsection{Preliminaries}

Before surveying the literature on firm dynamics and innovation, this section revises some critical concepts.

Time. Since the Industrial Revolution, modern economies live in a permanent state of innovation and progress. In this sense, innovation has to be understood as a dynamic process fueling technological developments. For this reason, the literature on economic growth belongs to the family of dynamic stochastic general equilibrium (DSGE) models where time is a fundamental dimension of the economic system. Static models are some times used as a shortcut, however, by construction they miss a fundamental dimension of the innovation process: It takes a long time to implement, adopt and diffuse new technologies. ${ }^{1}$

${ }^{1}$ Different authors have measured the time it takes for innovation to diffuse. Comin and Hobijn (2010) estimate that new technologies take around fifty years to be adopted 
Aggregate macroeconomic and microeconomic data are generally collected monthly, quarterly or annually. As a consequence, models designed to simulate and evaluate innovation policies often assume that time is discrete. In this chapter instead, we choose to follow the main tradition of economic growth theory and assume that time is continuous. Moreover, we abstract from aggregate shocks, even when some of the models reviewed originally embody aggregate stochastic processes.

Firm Heterogeneity. New technologies are fundamentally developed and implemented by the private sector. In a decentralized world, technical progress operates through the creation and destruction of products, plants and firms. In this sense, understanding the innovation process requires a minimum degree of firm heterogeneity and a good understanding of the dynamics of firms and markets.

The recent literature on firm dynamics usually models firm heterogeneity by assuming that the productivity of a firm can be characterized by some variable $z$. A firm entering the economy at time $t$ draws its initial $z$, let us denote it by $z_{t}$, from some known entry (density) distribution $\psi_{t}(z)$. The entry distribution may be evolving over time. The support of the entry distribution is usually assumed to be in the real line, with some lower bound $\zeta_{t} \geq 0 .^{2}$ As time passes, the productivities of these firms evolve following independent Markov processes. Equilibrium at time $t$ will be then characterized as an equilibrium productivity (density) distribution that we denote by $\phi_{t}(z)$, for $z \geq z_{t}^{*}$, where $z_{t}^{*}$ is the productivity of the least productive firm still surviving on the market. This is commonly called the cut-off productivity level.

In this review, we mainly concentrate on the study of economies where the productivity of a firm is time invariant, meaning that at entry firms draw a productivity $z$ from $\psi_{t}(z)$, for $z \geq \zeta_{t}, \zeta_{t} \geq 0$, and keep this productivity constant all along their active life. In stationary economies, the entry distribution $\psi(z)$ and the lower bound of its support $\zeta$ are assumed to be time invariant. Instead, in growing economies the entry distribution $\psi_{t}(z)$

worldwide after their invention. When compared to the US, Comin et al. (2008) estimate that the lag in the use of new technologies by most countries is measured in decades. Adams (1990) measures in roughly 20 years the time it takes academic knowledge to contribute to productivity growth. Mansfield (1989) quantifies in 8 years the mean adoption delay of twelve mayor 20th-century innovations. Jovanovic and Lach (1997) estimate at $8.1 \%$ the annual diffusion rate of new products.

2 Some papers, like Melitz and Redding (2015), assume also that the support of entry distribution has a finite upper bound. 
will move overtime guided by some form of spillover, as well as the lower bound of its support $\zeta_{t}$. Hence, a stationary entry distribution will not result in growing average productivity.

A standard assumption in this literature is that a firm with productivity $z$ employs some flexible production factor $x$ to produce output $y$. In the following, inputs and output of a firm with productivity $z$ will be denoted $x(z)$ and $y(z)$, respectively. In perfectly competitive economies, this technology is assumed to have decreasing returns on $x$. However, under monopolistic competition, including also other forms of imperfect competition, technology is frequently assumed to be linear on $x$. Hopenhayn and Melitz, respectively assume $y(z)=z x(z)^{\alpha}, \alpha \in(0,1)$ and $y(z)=z x(z)$. Following Collard and Licandro (2018), we will in some sections assume that $y(z)=F(z, x(z))$, with $F($.$) being a Neoclassical$ technology.

This literature often abstracts from capital accumulation by assuming that labor $\ell$ is the sole production factor, i.e. $x=\ell$. Hopenhayn (2014) generalizes it to a two production factor economy, with $x=F(k, \ell) ; k$ represents capital and $F(k, \ell)$ is assumed to be a Neoclassical technology.

In line with the Neoclassical growth framework, we survey first models where the productivity of firms is stationary or evolves exogenously, to then study models where firm heterogeneity is guided by innovation and technological developments.

Entry Cost, Innovation and Capital Reversibility. It is generally assumed that firms have to pay some entry cost before they draw productivity $z$ from $\psi_{t}(z)$. On top of that, the entry cost is frequently assumed to be sunk, i.e. the investment realized to create the firm is irreversible: When a firm closes down, nothing is recovered from this investment. Moreover, it is usual that net revenues of operative firms are strictly positive, implying that fixed production costs need to be assumed for the least productive firms to exit. ${ }^{3}$

Interestingly, the sunk entry cost, even when fully irreversible, can be interpreted as a form of intangible investment. Since operative firms make positive profits at equilibrium, the value of the firm, namely the expected

${ }^{3}$ In Hopenhayn (1992), net revenues are strictly concave due to decreasing returns to labor; at equilibrium, low productivity firms optimally hire few workers making net revenues strictly positive. In Melitz (2003), monopoly profits are strictly concave implying that low productive firms also optimally hire few workers making net revenues strictly positive. 
discounted flow of profits, is the value of the associated intangible investment. Firms close down and exit when the value of their intangible capital is zero.

As an alternative and consistent with national accounts, Collard and Licandro (2018) assume that the entry cost is a form of capital investment (tangible and intangible), with capital being partially reversible, i.e. it has a market value smaller than the replacement cost. Under very general assumptions about firms'technology, they show that aggregate technology is Neoclassical on aggregate capital and labor. Moreover, since capital is partially reversible, no fixed production cost is needed for the least productive firms to exit: Firms exit when the value of being operative is smaller than the market value of capital.

In the endogenous growth literature, when innovation is assumed to be undertaken by new entrant firms, $R \& D$ investment is a form of entry cost. ${ }^{4}$ Firms have to invest in R\&D in order to innovate and then enter the economy. In Romer (1990), new firms innovate by creating a new variety. Since firms are never displaced in the Romer's model, the R\&D investment can be seen as fully reversible. Patents can be transferred at no cost. In the Schumpeterian model of Aghion and Howitt (1992) or in the Grossman and Helpman (1991)'s quality-ladder model the entering firm displaces an incumbent firm, which is known as business-stealing effect. R\&D investments are then fully irreversible in these two models.

One-Final-Good Economy. Macroeconomic models are designed to understand the behavior of GDP as measured by national accounts. Consistently, in the tradition of the Neoclassical growth theory, an economy is modeled as producing a sole final good, directly associated to GDP in the data. The final good is then allocated to different uses, such as consumption or investment. Macroeconomic models of heterogeneous firms belong to this tradition.

For example, in Hopenahyn (1992) the production side of an economy is modeled as a mass of heterogeneous firms that produce the sole final good under perfect competition. Hence, in these economies, firm's technology has decreasing returns on labor, in line with the Lucas (1978)'s span of control model.

\footnotetext{
${ }^{4}$ In Sect. 4.4, some models of innovation by incumbents, where R\&D does not play the role of an entry cost, are also surveyed. Another example of such models can be found in Akcigit and Kerr (2017).
} 
Alternatively, in the monopolistic competitive approach inspired in Dixit and Stiglitz (1977), a perfectly competitive, representative firm produces the sole final good by the mean of a constant elasticity of substitution technology defined on a continuum of heterogeneous intermediary inputs, which are assumed to be gross substitutes. The market for intermediary inputs is assumed to be monopolistically competitive. Each heterogeneous intermediary firm has monopoly power on the production of a particular intermediary input and owns a constant return to scale technology defined on a vector of production factors (usually labor only). ${ }^{5}$ An alternative and isomorphic way of representing the same economy is to assume that the monopolistically competitive firms produce a continuum of final consumption goods that households order by the mean of a constant elasticity of substitution utility function. Consumption in national accounts is then interpreted as the aggregate of all the different consumption goods, aggregated by the mean of household preferences.

Aggregation. As shown by Hopenhayn and Collard and Licandro (2018), most of these economies share some simple aggregation properties that cause aggregate technology to be Neoclassical in exogenously driven growth models. These aggregation properties are shared with most endogenous growth models, where aggregate technology indeed belongs to the family of AK production functions. The main implication is that aggregate conditions are quite standard despite the complexity added by firm heterogeneity.

Spillovers. In the Neoclassical growth model, technical progress is a gift offered by Nature that instantaneously diffuses over the whole economy without limit: All firms and countries may access the frontier technology. In particular, the representative firm benefits from it without paying any cost. In this sense, technical progress in the Neoclassical growth model is nothing else than spillovers! Of course, since technical progress is part of the environment, and Nature gives rise to it without facing any trade-off, a perfectly competitive economy reacts to it optimally. Hence, in the Neoclassical growth mode technical progress diffuses through inconsequential spillovers.

However, when innovations are added to the picture endogenizing the rate of technical progress, spillovers become consequential. For example,

\footnotetext{
5 This framework has been extended to alternative forms of imperfect competition, see Atkeson and Burstein (2008) and Impullitti and Licandro (2018).
} 
endogenous growth in the learning-by-doing model is based on a particular form of spillover: the state of technology depends on past capital production. Consequently, investors (i) do not internalize the effect of their actions on technical progress, (ii) invest less than optimal and (iii) the economy grows at a rate smaller than the optimal growth rate. Similarly, in Romer (1990) expanding-product-variety model, innovators increase the mass of intermediary inputs, which affect the productivity of final producers through another form of spillover externality.

In the Schumpeterian and quality-ladder models, the technology of innovators builds upon the pre-existing state of knowledge. This operates as a form of spillover, since the knowledge that innovators create, indeed, flows back to the economy improving the innovation technology of the following innovators. Hence, when innovators substitute Nature, investing resources to make the technology progress, since they do not internalize knowledge spillovers, spillovers become consequential.

Technological spillovers result from a fundamental property of knowledge, the so-called non-rivalry: The use of some knowledge by an individual or firm does not prevent another by using it simultaneously. The fact that an engineer is using the Pythagoras theorem to calculate some structures does not impede others from using it too. For this fundamental reason, a model designed to evaluate innovation policies has to include knowledge spillovers, as well as the potential distortions generated by the policies, in particular those addressed to protect intellectual property rights. In this sense, it is important to understand that innovation policies have to be analyzed in a second-best framework.

Embodied Technical Change. The evidence of a permanent decline in the price of durable goods (including equipment investment, structures, durable consumption and some forms of intangible capital), relative to the price of non-durable consumption and services, gave raise to a large literature stressing the importance of modeling the economy as a twosector model with durable and non-durable goods. The standard way of modeling is in line with Greenwood et al. (1997). ${ }^{6}$

As aforementioned, in the Neoclassical growth model technical progress is disembodied: new technologies diffuse all over the economy at no cost. Instead, when technical progress is embodied in capital, it requires investments to diffuse. The frontier of technology moves in

${ }^{6}$ See also Felbermayr and Licandro (2005). 
the investment sector, but investments are needed to allow for technical progress to diffuse to the consumption sector.

Finally, in the vintage capital literature the gift of Nature is only addressed to new capital units. ${ }^{7}$ Investment is key for an economy that wants to benefit from the progress of technology, since technical progress does not spillover previously produced capital. For this reason, technical progress in the vintage capital model, is said to be embodied in new capital. Moreover, a perfectly competitive vintage capital economy optimally reacts to technical change. The fact that the gift of Nature only flows over the capital producing industry is also inconsequential (Solow, 1962).

\subsection{Firm Dynamics and the Neoclassical Model}

The seminal work of Jovanovic (1982) and Hopenhayn (1992), and the subsequent application to international trade by Melitz (2003), gave raise to an extensive literature on the macroeconomic implications of firm dynamics pointing to the fundamental role of market selection on economic performance and welfare. Even if Jovanovic (1982) stresses the role of incomplete information and learning, in the Hopenhayn (1992) framework heterogeneous firms operate in perfectly competitive markets, making selection to be optimal by construction. In the Melitz (2003) model of monopolistic competition, instead, selection interacts with different types of market frictions, making welfare gains from selection less obvious.

As mentioned, time is assumed to be continuous and denoted by $t$, with $t=0$ being the initial time. Population is assumed to be constant and normalized to one, implying that aggregate variables are measured in per capita terms. There is a sole final good which is adopted as numeraire, even if in some sections of the chapter the implications of multiple final goods (consumption and investment, for example) are discussed.

A representative household, with additively separable constant intertemporal elasticity of substitution (CIES) preferences, inelastically offers one unit flow of labor. Households face perfect financial markets with riskless interest rate $r_{t}$. The saving behavior of the representative

7 See Solow (1962) and Solow et al. (1966), and more recently, Boucekkine et al. (1997, 2005) and Gilchrist and Williams (2000). Bambi et al. (2014) develop an endogenous growth model of vintage technologies. 
household then reduces to the well-known Euler equation

$$
\frac{\dot{c}_{t}}{c_{t}}=\sigma\left(r_{t}-\rho\right)
$$

where $c_{t}$ is per capita consumption, $\sigma>0$ is the intertemporal elasticity of substitution and $\rho>0$ is the subjective discount rate. When financial markets value time more than individuals subjectively do, i.e. when $r_{t}>\rho$, individuals optimally save and postpone consumption, making $\frac{\dot{c}_{t}}{c_{t}}>0$. The intensity of consumption postponement depends on the intertemporal elasticity of substitution. In the extreme case of intertemporal perfect substitutability, when $\sigma$ goes to $\infty$, for a given difference $r_{t}-\rho>0$, individuals postpone any consumption, making $\frac{\dot{c}_{t}}{c_{t}}=\infty$. In the other extreme of perfect complementarity, when $\sigma$ goes to 0 , any given difference $r_{t}-\rho>0$ has no effect on the consumption path that will be in any case constant.

\subsubsection{Ramsey-Hopenhayn Model}

The Economy. A continuum of perfectly competitive heterogeneous firms produces at time $t$ a sole final good using capital as a fixed production factor and labor as a flexible factor. ${ }^{8}$

A firm, when associated to a particular unit of capital, has a time invariant productivity $z$, with $\phi_{t}(z)$ representing the equilibrium (density) productivity distribution, for $z$ in the support $\left(z_{t}^{*}, \infty\right)$; the so-called cutoff productivity $z_{t}^{*}$ is endogenous. To fix ideas, let us see each unit of capital as a plant. Firms may own different plants with different productivity. $\phi_{t}(z)$ is the distribution of productivity across plants. Buying one unit of capital costs $\eta$ units of the final good, $\eta>1$. However, when transformed back into the final good, the capital unit is worth just one unit. In line with the misallocation literature, investment distortions are measured by $\eta-1>0 .{ }^{9}$ In this sense, investment is partially sunk, since firms cannot recover their investment fully when a plant closes down.

8 This section is inspired in Collard and Licandro (2018).

9 See Hsieh and Klenow (2009). For a survey on this literature, see Restuccia and Rogerson (2017). Hopenhayn (2014) shows the intrinsic relation between the literature on firm dynamics and the literature on misallocation. 
A plant with productivity $z$ has access to technology ${ }^{10}$

$$
y_{t}(z)=A_{t} z^{\alpha} \ell_{t}(z)^{1-\alpha},
$$

with $\alpha \in(0,1) .{ }^{11}$ The state of technology $A_{t}$ exogenously grows at the rate $(1-\alpha) \gamma, \gamma>0$. Variables $y_{t}(z)$ and $\ell_{t}(z)$ denote output and employment, respectively. It is easy to see that, for a given wage rate $w_{t}$, the optimal labor demand is

$$
\ell_{t}(z)=\left(\frac{(1-\alpha) A_{t}}{w_{t}}\right)^{\frac{1}{\alpha}} z .
$$

Since operative plants produce all the same final good, per capita production (remind that population has been normalized to one) is

$$
y_{t}=k_{t} \int_{z_{t}^{*}}^{\infty} y_{t}(z) \phi_{t}(z) \mathrm{d} z,
$$

where $k_{t}$ represents the mass of operative plants, which by assumption is equal to the stock of capital per capita.

Labor market clearing implies that the equilibrium wage rate, plant profits and per capita output are, respectively,

$$
w_{t}=(1-\alpha) A_{t}\left(\bar{z}_{t} k_{t}\right)^{\alpha}, \quad \pi_{t}(z)=\alpha A_{t}\left(\bar{z}_{t} k_{t}\right)^{\alpha-1} z \text { and } y_{t}=A_{t}\left(\bar{z}_{t} k_{t}\right)^{\alpha},
$$

where the average productivity of firms is

$$
\bar{z}_{t}=\int_{z_{t}^{*}}^{\infty} z \phi_{t}(z) \mathrm{d} z .
$$

At equilibrium aggregate technology is Cobb-Douglas with total factor productivity given by $A_{t} \bar{z}_{t}^{\alpha} .{ }^{12}$ Wages and profits are equal to the marginal product of labor and capital, respectively. Selection raises the average

10 The argument below applies to any Neoclassical technology $F(z, \ell)$.

11 This technology is in line with the span of control assumption in Lucas (1978).

12 Alternatively, Collard and Licandro (2018) interpret productivity $z$ as being embodied in capital, meaning that $\bar{z}$ represents the average quality of the physical capital $k$ and $\bar{z} k$ measures capital in quality adjusted units. 
productivity of firms, increasing output $y_{t}$, wages $w_{t}$, and average profits $\pi_{t}\left(\bar{z}_{t}\right)$.

Selection. New plants buy one unit of capital and then draw productivity $z$ from the entry distribution $\psi(z)$, for $z$ in the positive real line. Let us assume $\psi(z)$ is Pareto, with tail parameter $\kappa>1$ and expected productivity at entry equal to one (which implies that the lower bound of the support of $z$ is $\frac{\kappa-1}{\kappa}$ ). As shown in Collard and Licandro (2018) under some general conditions, for all time $t \geq 0$, the equilibrium cut-off productivity is $z_{t}^{*}=z^{*}$ (time invariant) and the equilibrium productivity distribution is the entry distribution truncated at $z^{*}$; i.e.,

$$
\phi_{t}(z)=\frac{\psi(z)}{1-\Psi\left(z^{*}\right)},
$$

for all $t \geq 0$ and for $z \in\left(z^{*}, \infty\right)$, where $\Psi(z)$ is the cumulative of $\psi(z) .{ }^{13}$

Since profits are linear on $z$ and the equilibrium $z^{*}$ is time invariant, the value of any operative plant $v_{t}(z)$ is linear on $z$ too. Notice that operative plants at $t=0$ will optimally like to be operative forever. At equilibrium, then

$$
v_{t}(z)=v_{t} z, \quad \text { and } \quad v_{t}=\int_{t}^{\infty} \pi_{s}(1) \mathrm{e}^{\int_{s}^{\infty}\left(r_{h}+\delta\right) \mathrm{d} h} \mathrm{~d} s
$$

where $v_{t}$ is the expected discounted flow of profits of a firm with productivity $z=1$ and $\delta>0$ is an exogenous exit rate, equivalent to the physical depreciation rate in the Neoclassical model. The path of $v_{t}$ depends on the path of the aggregates.

The equilibrium cut-off productivity $z^{*}$ results then from combining the exit and free entry conditions

$$
\begin{gathered}
v_{t} z^{*}=1 \\
\Psi\left(z^{*}\right)+\left(1-\Psi\left(z^{*}\right)\right) v_{t} \bar{z}=\eta
\end{gathered}
$$

13 There are two critical assumptions behind this result. Firstly, the economy is assumed to be at steady state at the initial time $t=0$. Secondly, a permanent and unanticipated shock makes the economy become more selective. The first is a very usual assumption in macro dynamics. The second restrict the analysis to policies that promote selection, which in this framework, are welfare improving. 
From the exit condition $\left(\mathrm{EC}_{\mathrm{RH}}\right)$, the value of the marginal plant, $v_{t} z^{*}$, is equal to the value of capital (which is equal to one, since capital can be transformed back into one unit of the final good). From the free entry condition $\left(\mathrm{FE}_{\mathrm{RH}}\right)$, the investment cost $\eta$ has to be equal to the expected value of entry. Notice that a new plant expects to get a productivity smaller than $z^{*}$ with probability $\Psi\left(z^{*}\right)$, in which case immediately exits and recovers one. Otherwise, with probability $1-\Psi\left(z^{*}\right)$, the plant will produce and get an expected value $v_{t} \bar{z}$.

The equilibrium cut-off productivity results from combining $\left(\mathrm{EC}_{\mathrm{RH}}\right)$ and $\left(\mathrm{FE}_{\mathrm{RH}}\right)$ to get rid of $v_{t}$. Collard and Licandro (2018) show that under very general conditions the solution exists and is unique, with $z^{*}>$ $1 / \eta$ depending only on the entry distribution $\psi(z)$ and the investment distortion $\eta-1 .^{14}$ Both, a reduction in investment distortions and an increase in the variance of the entry distribution raise $z^{*}$ by reducing the cost of entry and increasing the likelihood of reaping the benefits of a high productivity draw, respectively.

Aggregate Economy. Since the capital of exiting plants (those with productivity smaller than $z^{*}$ ) is fully recycled, the efficiency condition reads

$$
y_{t}+\Psi\left(z^{*}\right) e_{t}=c_{t}+\eta e_{t},
$$

where $e_{t}$ represents entry, i.e., the mass of new plants created at time $t$. Each new plant needs a unit of capital, which costs $\eta$. Moreover, a fraction $\Psi\left(z^{*}\right)$ of them close down and their capital reverts to the economy, being consumed or invested. ${ }^{15}$

Capital per capita evolves following

$$
\dot{k}_{t}=\left(1-\Psi\left(z^{*}\right)\right) e_{t}-\delta k_{t},
$$

14 This result generalizes the separation result in Melitz (2003), making selection to be independent of the path of the aggregates.

15 It is implicitly assumed that the selection process at any time $t$ repeats infinitely until all firms get a productivity larger than $z^{*}$. Collard and Licandro (2018) use the alternative assumption that the capital of plants closing down at $t$ cannot be recycled until $t+\mathrm{d} t$, in which case the dynamics of Ramsey-Hopenhayn economy is slightly different even if it still shows standard (saddle-path) monotonic convergence properties. 
where $\delta>0$ is the physical rate of capital depreciation. The feasibility condition results from combining the previous two equations

$$
\dot{k}_{t}=\frac{1-\Psi\left(z^{*}\right)}{\eta-\Psi\left(z^{*}\right)}\left(A_{t}\left(\bar{z} k_{t}\right)^{\alpha}-c_{t}\right)-\delta k_{t}
$$

Notice that the rate at which the final good transforms into physical capital is smaller than one, since investment distortions make the selection process costly.

Combining the exit condition (EC_RH) and the Euler equation (EE), the last one reads

$$
\frac{\dot{c}_{t}}{c_{t}}=\sigma\left(z^{*} \alpha A_{t}\left(\bar{z} k_{t}\right)^{\alpha-1}-\rho-\delta\right),
$$

where the marginal product of capital corresponds to the profits of the marginal plant $z^{*}$.

Given an initial $k_{0}>0$, the equilibrium cut-off $z^{*}$ and the associated average productivity $\bar{z}$, an aggregate equilibrium of the RamseyHopenhyan model is a path $\left\{c_{t}, k_{t}\right\}$, for $t \geq 0$, such that both (EE') and (FC) conditions hold (together with a transversality condition) It is important to notice that $(\mathrm{FC})$ and $(\mathrm{EE}$ ') are the same as in the Neoclassical growth model, with a few constant terms depending on the equilibrium value of $z^{*}$. At the balanced growth path the economy then grows at the constant rate $\gamma$.

Collard and Licandro (2018) show that a policy that decreases investment distortions, by making the economy more efficient, increases capital, output and consumption (measured in efficiency units) at the balanced growth path, generating steady state welfare gains. Moreover, the dynamic system has standard stability properties, meaning that the economy monotonically converges to a unique balanced growth path.

Transitional Dynamics. Let us assume the economy was initially at steady state with past investment distortions given by $\eta_{p}>1 .{ }^{16}$ For simplicity, the rate of technical progress is $\gamma=0$. Consistently, the economy at the initial time $t=0$ has a distribution of firms $\phi_{p}(z)=$ $\psi(z) /\left(1-\Psi\left(z_{p}^{*}\right)\right)$ in the support $z \in\left(z_{p}^{*}, \infty\right)$, as well as an initial stock of physical capital $k_{p}$; both $z_{p}^{*}$ and $k_{p}$ solve the steady state equilibrium conditions.

16 These distortions may represent different forms of barriers to entry. 


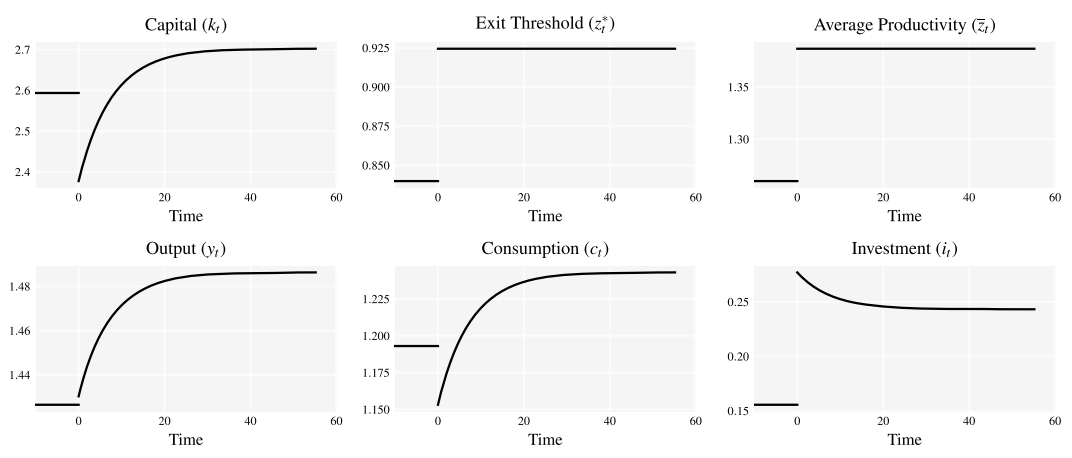

Fig. 3.1 Transition dynamics: permanent decline in investment distortions $(\eta)$ (Note This figure was obtained setting $\sigma=1, \rho=0.05, \delta=0.06, \alpha=0.3, \kappa=3$ and the initial investment distortion is $\eta=1.2$. We then consider a $5 \%$ once for all reduction in $\eta$ )

Let us also assume that from $t=0$ a new policy permanently reduces investment distortions. For simplicity, let us refer to the new policy as $\eta$, with $\eta<\eta_{p}$. The cut-off productivity jumps then to a new steady state $z^{*}>z_{p}^{*}$ and the equilibrium distribution jumps to $\phi(z)=\psi(z) /(1-$ $\left.\Psi\left(z^{*}\right)\right)$.

Interestingly, the initial stock of capital is partially destroyed because of selection, implying that

$$
k_{0}=\left(1-\frac{\eta-1}{\eta-\Psi\left(z^{*}\right)} \Phi_{p}\left(z^{*}\right)\right) k_{p}<k_{p} .
$$

Of course, the average productivity $\bar{z}$ jumps up at $t=0$ making output to increase at the initial time. Similarly to the Neoclassical growth model, consumption at the initial time jumps down to the new saddle path solution converging monotonically with capital to the new higher steady state.

\subsubsection{Monopolistic Competition}

This section builds on a close economy of the Melitz (2003) type.

The Economy. Heterogeneous intermediary firms produce a continuum of intermediary inputs used in the manufacture of a sole final 
good. The final good is produced by a representative competitive firm under perfect competition; the final good is used as numeraire. Intermediary inputs, indeed, in line with Dixit and Stiglitz (1977), are produced under monopolistic competition. For comparability, we adopt a similar notation as in the previous section (Fig. 3.1).

There is a mass $m_{t}$ of heterogeneous intermediary firms. Firms differ in their productivity $z$, producing each a differentiated intermediary input by the mean of the following linear technology

$$
y_{t}(z)=A z \ell_{t}(z)
$$

where $y_{t}(z)$ and $\ell_{t}(z)$ represent output and labor of a firm with productivity $z$, respectively; the state of technology $A>0$ is assumed to be constant. ${ }^{17}$ As in the previous sections, operative firms have productivity $z \geq z_{t}^{*}$.

The sole final good is allocated to consumption $c_{t}$ only and it is produced by a mass unit of identical perfectly competitive final firms by the mean of the constant elasticity of substitution (CES) technology

$$
c_{t}=\left(m_{t} \int_{z_{t}^{*}}^{\infty} y_{t}(z)^{\frac{\varrho-1}{\varrho}} \phi_{t}(z) \mathrm{d} z\right)^{\frac{\varrho}{\varrho-1}}
$$

defined on a mass $m_{t}$ of intermediary inputs, with constant elasticity of substitution $\varrho>1$.

Final firms are price takers in both the final and the intermediary markets, optimally demanding of each intermediary input the quantity

$$
y_{t}(z)=p_{t}(z)^{-\varrho} c_{t} .
$$

The demand elasticity of any intermediary input is equal to the elasticity of substitution across varieties. More substitutable intermediary inputs are, more the final firm reacts to changes in input prices. Love-for-variety, in the sense of Dixit-Stiglitz, means that firms would like to use all available intermediary inputs, with relative quantities depending on relative prices.

Intermediary firms have monopoly power in the production of intermediary inputs. They maximize profits subject to the demand function

17 It is easy to extend the Melitz model to an environment where the aggregate state of technology $A_{t}$ grows at a constant exogenous rate, as assumed in the previous section. 
above, optimally setting price

$$
p_{t}(z)=\frac{\varrho}{\varrho-1} \frac{w_{t}}{A z}
$$

Intermediary firms charge a markup $\frac{\varrho}{\varrho-1}>1$ over marginal costs $\frac{w_{t}}{A z}$. More productive firms set a lower price, producing and selling more. The markup is inversely related to the demand elasticity.

An important property of the monopolistic competitive model is that all monopolistically competitive firms charge the same markup, implying that their relative prices are equal to their relative marginal productivities. The direct implication is that the allocation of production factors within a monopolistically competitive sector is efficient, since relative prices are equal to relative marginal productivities. ${ }^{18}$ Of course, the allocation of production factors between the monopolistic competitive sector and other sectors of the economy may be distorted because of the markup. A recent literature stresses the role played by the dispersion of markups on the allocation of resources within an industry. ${ }^{19}$

Aggregating over intermediary firms, it can be shown that consumption per capita, the wage rate and total net revenues are

$$
c_{t}=A m_{t}^{\frac{1}{\varrho-1}} \bar{z}_{t} L_{t}, \quad w_{t}=\frac{\varrho-1}{\varrho} A m_{t}^{\frac{1}{\varrho-1}} \bar{z}_{t} \quad \text { and } \quad \pi_{t}=\frac{1}{\varrho} c_{t},
$$

with average productivity defined as

$$
\bar{z}_{t}=\left(\int_{z_{t}^{*}}^{\infty} z^{\varrho-1} \phi_{t}(z) \mathrm{d} z\right)^{\frac{1}{\varrho-1}}
$$

where $L_{t}$ represents the share of total labor allocated to production (excluded any fixed production costs). The mass of intermediary inputs $m_{t}$ shows up in the aggregate technology as an externality, usually referred in this literature as love-for-variety. The more intermediary inputs are available for final production, the more efficient final production is. Moreover, selection positively affects output since it raises the average productivity of firms $\bar{z}_{t}$.

18 See Koeninger and Licandro (2006) and Epifani and Gancia (2011).

19 See Impullitti and Licandro (2018). 
The production of the consumption good requires both labor and intermediary inputs, which mass is represented by $m_{t}$. Wages are the return to labor and profits the return to the investment required to create an intermediary input (the entry cost). It is possible to interpret the mass of intermediary inputs as the stock of intangible capital. In this framework, the distribution of income between intangible capital and labor critically depends on the elasticity of substitution across intermediary inputs. An increase in substitutability reallocates income from intangible capital to labor.

Net revenues of firm $z$ are, indeed,

$$
\pi_{t}(z)=\frac{1}{\varrho} \frac{c_{t}}{m_{t}}\left(\frac{z}{\bar{z}_{t}}\right)^{\varrho-1} .
$$

Notice that net revenues of the average firm $\bar{z}_{t}$ are equal to average net revenues $\pi_{t} / m_{t}$. Firms with productivity larger than the mean make profits larger than the average profit.

Selection. Following Melitz (2003), let us assume intermediary firms have to pay a sunk entry cost $w_{t} f_{e}$ to enter, $f_{e}>0$ being the amount of labor required to create a new intermediary input. After entry, firms draw a productivityz from an entry distribution $\Psi(z)$ with support in the real line. Since new firms produce new varieties, the sunk entry cost may be interpreted as an $\mathrm{R} \& \mathrm{D}$ investment; i.e. the investment required to be able to produce the new input variety. Of course, if the technology producing the new intermediary input is not productive enough, the firm will close down making the value of this R\&D investment to be zero ex-post.

At any time $t$, intermediary firms require a fixed amount of labor $f$, $f>0$, to be operative, facing then a fixed production cost $f w_{t}$. At the steady state of the Melitz model, the marginal firm $z^{*}$ is defined by the (zero-profit) exit condition

$$
\pi\left(z^{*}\right)=\frac{1}{\varrho} \frac{c}{m}\left(\frac{z^{*}}{\bar{z}}\right)^{\varrho-1}=f w
$$

Any firm with productivity $z<z^{*}$ exits since net revenues are not large enough to cover the fixed production costs. Notice that, for any operative firm with $z \geq z^{*}$, profits can then be expressed in relation to the marginal 
firm as

$$
\pi(z)-f w=\left(\left(\frac{z}{z^{*}}\right)^{\varrho-1}-1\right) f w .
$$

Any operative firm with productivity larger than $z^{*}$ makes positive profits, equilibrium profits being proportional to the fixed production cost.

The value $v(z)$ of a firm with productivity $z$ at steady state is the expected discounted flow of profits, which collapses to

$$
v(z)=\frac{\left(\left(\frac{z}{z^{*}}\right)^{\varrho-1}-1\right) f w}{r+\delta},
$$

since expected profits are discounted at $r+\delta$, where $\delta>0$ is the Poisson destruction rate of any operative firm. ${ }^{20}$

The free entry condition makes expected profits equal to the entry cost

$$
\int_{z^{*}}^{\infty} v(z) \mathrm{d} \Psi(z)=f_{e} w
$$

Remember that a firm is assumed to invest in intangibles before knowing its productivity. Under the assumption that the entry distribution is Pareto, i.e., $\Psi(z)=1-\left(\frac{\zeta}{z}\right)^{\kappa}$, with $\kappa>1$ and $\zeta>0$, by combining the exit $\left(\mathrm{EC}_{\mathrm{M}}\right)$ and free entry $\left(\mathrm{FE}_{\mathrm{M}}\right)$ conditions, the steady state equilibrium cut-off becomes ${ }^{21}$

$$
z^{*}=\left(\frac{f}{f_{e}} \frac{1}{r+\delta}\left(\left(\frac{\kappa}{\kappa-1}\right)^{\varrho-1}-1\right)\right)^{\frac{1}{\kappa}} \zeta
$$

Any policy addressed to reduce the entry cost $f_{e}$ or the equilibrium interest rate $r$ makes the economy more selective.

${ }^{20}$ Notice that the R\&D entry cost, even if sunk, it has a value. We will interpret it as a form of intangible capital, which has different value depending on the productivity of the firm.

21 At steady state, the interest rate $r=\rho$ is constant. 
There is a stationary allocation of labor to production and R\&D investments, such that at the stationary equilibrium the mass of new intermediary firms is equal to the mass of exiting firms and the labor market clears. At the stationary equilibrium of the Melitz model, the mass of intermediary firms is given by

$$
m=\left(\varrho-1+\frac{\delta+r\left(\frac{\kappa-1}{\kappa}\right)^{\varrho-1}}{r+\delta}\right)^{-1} \frac{1}{f}\left(\frac{\kappa-1}{\kappa}\right)^{\varrho-1} .
$$

In the Melitz model, the entry (R\&D) cost depends on wages, which raises with selection. A more selective economy faces then a larger entry cost, which reduces the incentives to enter. This mechanism causes the economy to converge to a stationary mass of varieties and a stationary cutoff productivity. In Sect. 3.4, we analyze economies where both the cutoff productivity and the mass of intermediary inputs permanently increase, making the economy to be more innovative with growing productivity and output.

\subsubsection{Oligopolistic Competition}

In the monopolistic competitive framework, since intermediary firms share the same elasticity of substitution with each other, they all set the same time-invariant markup. As discussed by Koeninger and Licandro (2006), equal markups cause the monopolistic competitive allocation to be optimal. In this section, we discuss a close economy version of Impullitti and Licandro (2018), who develop an oligopolistic competitive framework allowing to understand the fundamental role of competition in shaping the relation between competition, selection and growth. ${ }^{22}$

The Economy. As in the monopolistic competitive model of Sect. 3.3.2, let us assume a sole consumption good is produced by a representative, perfectly competitive final firm by the mean of the constant elasticity of substitution (CES) technology with constant elasticity of substitution $\varrho>1$. Final firms are price takers in both the final and the intermediary markets, and optimally demand

$$
y_{t}(z)=p_{t}(z)^{-\varrho} c_{t},
$$

22 See also Peretto $(1996,2003)$ and Navas and Licandro (2011). 
where $c_{t}$ is total production, $y_{t}(z)$ and $p_{t}(z)$ are, respectively, the demand and price of intermediary input $z$. As before, the final consumption good is used as numeraire.

Following Impullitti and Licandro (2018), intermediary inputs, indeed, instead of being produced under monopolistic competition as in Melitz (2003), are produced under Cournot competition. There are $n$ firms, $n>1$, producing variety $z$ by the mean of technology

$$
y_{i, t}(z)=A z \ell_{i, t}(z)
$$

where $y_{i, t}(z)$ and $\ell_{i, t}(z)$ represent output and labor, respectively, of firm $i$ sharing productivity $z$ with other $n-1$ firms, its direct competitors; the state of technology $A>0$ is assumed to be constant. Of course, $y_{t}(z)=\sum_{i} y_{i, t}(z)$. As in the previous sections, operative intermediary inputs have productivity $z \geq z_{t}^{*}$.

The equilibrium price of the Cournot game, the same for all firms producing $z$, is

$$
p_{t}(z)=\frac{1}{\theta} \frac{w_{t}}{A z}
$$

where the inverse of the markup rate is $\theta=\frac{n-1 / \varrho}{n}$, with the markup going from $\frac{\varrho}{\varrho-1}$ to one, as the economy moves from monopolistic competition $(n=1)$ to perfect competition, when the number of firms goes to infinity.

Aggregating over intermediary firms, it can be shown that consumption per capita, the wage rate and total net revenues are

$$
c_{t}=A m_{t}^{\frac{1}{\varrho-1}} \bar{z}_{t} L_{t}, \quad w_{t}=\theta A m_{t}^{\frac{1}{\varrho-1}} \bar{z}_{t} \quad \text { and } \quad \pi_{t}=(1-\theta) c_{t},
$$

with average productivity defined as

$$
\bar{z}_{t}=\left(\int_{z_{t}^{*}}^{\infty} z^{\varrho-1} \phi_{t}(z) \mathrm{d} z\right)^{\frac{1}{\varrho-1}},
$$

where $L_{t}$ represents the share of total labor allocated to production (excluded the fixed production costs). For a given cut-off productivity $z^{*}$, the Cournot and the monopolistic competitive economies produce the same output. However, the share of labor is larger in the Cournot equilibrium, increasing with competition. An increase in competition reallocates income from (intangible) capital to labor. 
Selection. Interestingly, if the number of competitors $n$ is given, and the entry decision were jointly taken by the $n$ potential entrants, since profits of the marginal firm and expected profits of the potential entrant are both affected proportionally by $\theta$, the equilibrium cut-off at steady state is equal to $z^{*}$ in the equilibrium condition $\left(z_{M}^{*}\right)$ of the Melitz model. An exogenous change in the number of competitors $n$ does not affect selection. However, the fraction of labor allocated to production and the mass of intermediary inputs do. At steady state,

$$
L=\left(1+\frac{1-\theta}{\theta}\left(\frac{\delta+r\left(\frac{\kappa-1}{\kappa}\right)^{\varrho-1}}{r+\delta}\right)\right)^{-1}
$$

and

$$
m=\left(\frac{\theta}{1-\theta}+\frac{\delta+r\left(\frac{\kappa-1}{\kappa}\right)^{\varrho-1}}{r+\delta}\right)^{-1} \frac{1}{f}\left(\frac{\kappa-1}{\kappa}\right)^{\varrho-1}
$$

An increase in competition, measured by a raise in $\theta$, renders the static allocation more efficient, which moves labor toward production, increasing $L$. As an implication, less labor has to be allocated to create new varieties and to cover the fixed production costs, which implies a reduction in the mass of varieties.

In fact, Impullitti and Licandro (2018) analyze the problem under a very different perspective. They assume that the entry condition determines endogenously $n$. They also assume that there is a mass one of potential varieties, $m_{t}$ being the equilibrium mass. Potential entrants face a zero entry cost, but can only enter by producing a particular variety. At equilibrium, then, $1-m_{t}$ varieties are introduced at any time $t$; from them a fraction $1-\Psi\left(z^{*}\right)$ is produced, the others exit instantaneously. As a consequence, the equilibrium mass of varieties is determined by the stationary condition

$$
(1-m)\left(1-\Psi\left(z^{*}\right)\right)=\delta m .
$$

The free entry condition, instead, determines the number of competitor $n$ that produce any intermediary input. Since $n$ is determined before the productivity $z$ is known, all varieties have the same number of competitors at a balanced growth path equilibrium. 


\subsubsection{Physical and Intangible Capital}

An alternative way to Collard and Licandro (2018) of adding capital to the Hopenhayn model is in Hopenhayn (2014), which assumes that technology in (3.1) is defined in a composite production factor, such as,

$$
y_{t}(z)=z^{\alpha} F\left(k_{t}(z), \ell_{t}(z)\right)^{1-\alpha}
$$

where $F($.$) is a Neoclassical production function, k_{t}(z)$ and $\ell_{t}(z)$ are physical capital and labor employed for firm $z$. Hopenhayn (2014) shows that at equilibrium the aggregate technology is

$$
y_{t}=\left(\bar{z}_{t} m_{t}\right)^{\alpha} F\left(k_{t}, 1\right)^{1-\alpha}
$$

where $m_{t}$ is the mass of firms, $k_{t}$ is physical capital per capita and, as before, total labor is assumed to be equal to one. Notice that in this economy there are two forms of capital: physical capital $k_{t}$ and intangible capital $\bar{z}_{t} m_{t}$. The aggregate technology shows constant returns on labor, physical and intangible capital like in Corrado et al. (2009).

\subsection{Firm Heterogeneity IN MODEls WiTh INNOVATION}

\subsubsection{Romer Model}

Romer (1990) is based on the monopolistic competitive model developed by Dixit and Stiglitz (1977). Simplifying the model in Sect. 3.3.2, let us assume that identical intermediary firms (all with productivity $z=$ 1) monopolistically compete in the intermediary goods market. In this framework, a typical intermediary firm sets price and produces quantity

$$
p(z)=\frac{\varrho}{\varrho-1} w_{t} \quad \text { and } \quad y(z)=\left(\frac{\varrho}{\varrho-1} w_{t}\right)^{-\varrho} c_{t},
$$

respectively, where $w_{t}$ is the equilibrium wage rate and $c_{t}$ is aggregate consumption; $\varrho>1$ is the elasticity of substitution between intermediary inputs in the production of the final (consumption) good. Since intermediary firms are symmetric, they all set the same price and produce the same quantity. At equilibrium, the technology producing the final consumption good is

$$
c_{t}=A m_{t}^{v} L_{t},
$$


where the mass of intermediary inputs $m_{t}$ shows up as an externality and $L_{t}$ is the fraction of total labor allocated to the production of intermediary goods (there are no fixed productions costs in Romer). Aggregate technology shows the well-known love-for-variety externality: labor productivity in the final good sector raises with the mass of intermediary inputs $m_{t}$ at the rate $v=\frac{1}{\varrho-1} .^{23}$

Concerning innovation, let us assume that new intermediary varieties are produced by the mean of the R\&D technology

$$
\dot{m}_{t}=B m_{t}\left(1-L_{t}\right)
$$

where R\&D productivity $B$ is normalized to $B=(\varrho-1) A>0$ in order to simplify notation. Since the total labor supply is normalized to one, $1-L_{t}$ is the fraction of it allocated to research activities. The productivity of labor in the R\&D sector is critically assumed to depend on the mass of varieties $m_{t}$.

Let us define the state of knowledge as $k_{t}=m_{t}^{v}$. This allows us to interpret the Romer model in line with the Arrow (1962) learning-bydoing model. The economy learns by producing new varieties of the intermediary input. By doing so, technology becomes more productive in both the final good sector and the R\&D sector. Combining the two last equations, the feasibility condition becomes

$$
\dot{k}_{t}=A k_{t}-c_{t} .
$$

With the state of knowledge $k_{t}$, the economy produces $A k_{t}$, which can be consumed or allocated to the production of new knowledge- a form of intangible investment in the sense of Corrado et al. (2009). Notice that the normalization used to define $k_{t}$ as a function of $m_{t}$, including that of $B$, is inconsequential since knowledge has no natural unit. Technology in the Romer model then collapses to a one-good AK technology like in Rebelo (1991), sharing with Rebelo (1991) the conditions for a constant endogenous growth rate.

The optimal allocation of output $A k_{t}$ to consumption and savings (adopting the form of intangible investment) is as usual governed by the

23 Benassy (1996) adopts a more general framework, arguing that the love-for-variety externality $v$ may be any number between zero and infinity, independent of the elasticity of substitution $\varrho$. 
Euler equation (EE). At equilibrium, the return on $R \& D$ is

$$
r_{t}=\frac{1}{\varrho-1} A L_{t}
$$

decreasing in the elasticity of substitution, but increasing in the final good productivity parameter $A$ and the fraction of employment allocated to production. Notice that an increase in the degree of substitutability between intermediary goods raises the demand elasticity, reducing markups and profits and then decreasing the return on R\&D.

Substituting the equilibrium interest rate $r_{t}$ in the Euler equation (EE), it can be shown that the equilibrium growth rate is

$$
g=\sigma\left(\frac{A-\rho}{\varrho}-\rho\right)
$$

which negatively depends on the elasticity substitution $\varrho$, since it negatively affects the return on R\&D.

Firm Heterogeneity. The Romer model can be combined with the Melitz model to generate endogenous growth with firm heterogeneity, where selection by affecting the productivity of the final good sector will have a direct effect on the growth rate. Aggregating over intermediary firms,

$$
c_{t}=A \bar{z}_{t} k_{t} L_{t} .
$$

By assuming that productivity $B$ in the R\&D technology also depends on the average productivity $\bar{z}_{t}$, knowledge evolves following

$$
\dot{k}_{t}=A \bar{z}_{t} k_{t}\left(1-L_{t}\right),
$$

implying that the feasibility condition becomes

$$
\dot{k}_{t}=A \bar{z}_{t} k_{t}-c_{t} .
$$

Technology is AK with the marginal product of capital depending on selection through $\bar{z}_{t}$. The productivity gains through selection spillover to the consumption and R\&D sectors.

Since new firms draw their productivity from a time-invariant distribution, the productivity cut-off is constant at a balanced growth path, as well as the average productivity $\bar{z}$. As in the Romer model, the return 
on $\mathrm{R} \& \mathrm{D}$ and the growth rate depend on the average productivity $\bar{z}$. At steady state

$$
g=\sigma\left(\frac{A \bar{z}-\rho}{\varrho}-\rho\right)
$$

Selection makes the average productivity of capital larger, positively affecting the stationary growth rate. Those parameters positively affecting selection in the Melitz model, have here also a positive effect on the growth rate.

\subsubsection{Selection and Imitation}

Following Luttmer (2007), selection by itself can generate endogenous growth through imitation, since selection raises the productivity of incumbents. ${ }^{24}$ How do new firms react to this raise in productivity? Instead of drawing their productivity from a time-invariant distribution, the initial productivity of new firms is randomly drawn from an entry distribution that follows key moments of the incumbents equilibrium distribution. In this sense, new entrants learn from incumbents, imitating them, which causes productivity gains from selection to spillover innovators. A similar mechanism is used by Sampson (2016) to study the dynamic gains from trade. ${ }^{25}$

Let us follow the argument as developed by Sampson (2016), adapting his notation to be consistent with the notation in the previous sections. Sampson's model belongs to the family of monopolistic competitive models with labor as the sole production factor as developed by Melitz (2003) and reviewed in Sect. 3.3.2. Monopolistically competitive intermediary firms draw at entry a time-invariant labor productivity $z$ from an entry productivity distribution $\tilde{\Psi}_{t}(z)$, which differently from Melitz is assumed to be time dependent. Firms productivity is time invariant. However, due to selection, learning spillovers cause the distribution from which they draw their productivity follow these improvements in technology. Intermediary firms require a variable and fixed $(f)$ amount of labor to produce with $w_{t}$ being the equilibrium wage rate.

24 See also Luttmer $(2011,2012)$.

25 Gabler and Licandro (1979) develop the same idea in a framework similar to the one in the Ramsey-Hopenhayn model. 
As in Sect. 3.3.2, an intermediary firm with productivity $z$ sets price

$$
p_{t}(z)=\frac{\varrho}{\varrho-1} \frac{w_{t}}{z} .
$$

The zero profit condition implicitly defines the equilibrium cut-off productivity $z_{t}^{*}$,

$$
\frac{1}{\varrho} \frac{c_{t}}{m_{t}}\left(\frac{z_{t}^{*}}{\bar{z}_{t}}\right)^{\varrho-1}=f w_{t} .
$$

where $c_{t} / m_{t}$ is total consumption per firm (reminds that final output is fully allocated to consumption in the Melitz model).

Entry and Spillovers. Like in Romer (1990), potential entrants undertake R\&D activities to discover new varieties of intermediary inputs. They pay the R\&D (entry) cost $f_{e} w_{t}$, where $f_{e}>0$ is the amount of labor required to create a new intermediary input. $R \& D$ plays exactly the same role as an entry cost in the Melitz model. As usual in this literature, innovators are assumed to be protected by infinitely lived patents.

The critical assumption is the following: at any time $t$ innovators (the entrants), after paying the R\&D (entry) cost, draw a time-invariant productivity $z=\omega \bar{z}_{t}$, where $\bar{z}_{t}$ is the average productivity of incumbents and $\omega$ is a random variable distributed $\tilde{\Psi}(\omega)$. To fix ideas, let us assume that $\tilde{\Psi}(\omega)$ is Pareto with tail parameter $\kappa>1$. The only difference with the Melitz model is that the entry distribution $\Psi_{t}(z)=\tilde{\Psi}\left(z / \bar{z}_{t}\right)$, from which innovators draw $z$, is time dependent. That is, it depends on the time varying average productivity of incumbents. Innovators learn from incumbents through this particular type of spillover. ${ }^{26}$

Let us define the firm-specific relative productivity $\tilde{z}_{t}, \tilde{z}_{t}=\frac{z}{z_{t}^{*}}$, relative to the cut-off productivity $z_{t}^{*}$. Since the domain of $z$ is $\left(z_{t}^{*}, \infty\right)$, the domain of $\tilde{z}$ is $(1, \infty)$. In a growing economy, $z_{t}^{*}$ will be permanently moving to the right. Since firm's productivity is time invariant, the relative productivity of any firm will eventually converge to one on a finite time. When the lower bound is reached, the firm exits. Firms born at different moments in time belong to different technological cohorts, and since new cohorts are in average more productive, firms face a finite life,

\footnotetext{
${ }^{26}$ Imitation, since in this framework comes at a zero cost, can also be interpreted as diffusion.
} 
i.e. firms are losing value over time since their technology becomes slowly obsolete. ${ }^{27}$

Despite the fact that firms have a finite life, under the assumption that the entry distribution $\tilde{\Psi}(\omega)$ is Pareto, with tail parameter $\kappa>1$, the stationary productivity distribution is $\Phi_{t}(z)=1-\left(\frac{z_{t}^{*}}{z}\right)^{\kappa}$, for $z \geq z_{t}^{*}$. It is Pareto distributed, inheriting the tail parameter $\kappa$ from the entry distribution. Since at a balanced growth path selection moves cut-off productivity $z_{t}^{*}$ to the right, the equilibrium distribution $\Phi_{t}(z)$ is said to be a traveling wave. $^{28}$

Combining the exit and entry conditions with the Euler equation, Sampson (2016) shows that the steady state endogenous rate of technical progress is

$$
g=\frac{\sigma}{1+\sigma(\kappa-1)}\left(\frac{\varrho-1}{\kappa+1-\varrho} \frac{f}{f_{e}}-\rho\right) .
$$

Output per capita and consumption also grow at the rate $g$. An increase in the variance of the entry distribution (a reduction in $\kappa$ ), which is equivalent to an increase in the probability of exceptionally good innovations, or a reduction in the $\mathrm{R} \& \mathrm{D}$ (entry) cost $f_{e}$ both make the economy more selective. They increase the productivity of incumbent firms and through learning affects the productivity of innovators, inducing faster growth at steady state. An increase in the elasticity of substitution between intermediary inputs $\varrho$ makes the economy more competitive, also inducing more selection and growth.

27 In this sense, Sampson's model belongs to the vintage capital tradition. In Gilchrist and Williams (2000), for example, the productivity of new firms is drawn from a lognormal distribution, which mean has an exogenous trend. As shown by Boucekkine et al. (1997) and Boucekkine et al. (2005), vintage models involve (periodic) medium term movements which may be of relevance for the propagation of innovation. Bambi et al. (2014) extend this idea to vintage models with $\mathrm{R} \& \mathrm{D}$, showing that the long delay that innovation takes to diffuse generates medium term cycles, which has to be considered when evaluating the performance of innovation policies.

28 Even if not proved by Sampson (2016), under similar conditions as in Collard and Licandro (2018), the equilibrium distribution will likely be a truncated Pareto with cutoff productivity moving systematically to the right following the endogenous progress in technology. 


\subsubsection{Schumpeterian Model}

In the Schumpeterian framework, the dynamics of firms is modeled through the fundamental concept of creative destruction, which takes two forms: business stealing and crowding-out (or obsolescence).

In Aghion and Howitt (1992), the final consumption good $c_{t}$ is produced by the mean of technology

$$
c_{t}=\left(\int_{z_{t}^{*}}^{\infty}\left(z x_{t}(z)\right)^{\frac{\varrho-1}{\varrho}} \phi_{t}(z) \mathrm{d} z\right)^{\frac{\varrho}{\varrho-1}},
$$

where $x_{t}(z)$ represents the quantity of intermediary input $z$ used in the production of the final consumption $\operatorname{good} c_{t}, \varrho>1$ is the elasticity of substitution between them, and $\phi_{t}(z)$ is the equilibrium (density) distribution. Differently from Romer (1990), the mass of varieties $m_{t}$ is assumed to be time invariant and normalized to one, but the quality of goods $z$ is assumed to be heterogeneous. In the Schumpeterian model, R\&D activities are addressed to improve the quality of exiting varieties, which makes $\phi_{t}(z)$ time dependent, reflecting changes in technology induced by innovation.

Technology in the intermediary sector is assumed to be

$$
x_{t}(z)=A \ell_{t}(z),
$$

where parameter $A>0$ and $\ell_{t}(z)$ is labor allocated to the production of the intermediary input $z$. Notice that the variable change $y_{t}(z)=z x_{t}(z)$ brings us back to the Melitz model, where $y_{t}(z)$ is measured in quality adjusted units. ${ }^{29}$ Even if the Schumpeterian model is usually interpreted as a model of product innovation (addressed to improve the quality of intermediary goods), it can also be interpreted as a model of process innovation (addressed to reduce production costs).

Following the analysis in the previous sections, at equilibrium

$$
c_{t}=A \bar{z}_{t} L_{t},
$$

29 Price indexes are built with the objective of keeping quality constant, meaning that real quantities in national accounts are measured in quality adjusted units. 
where

$$
\bar{z}_{t}=\left(\int_{z_{t}^{*}}^{\infty} z^{\varrho-1} \phi_{t}(z) \mathrm{d} z\right)^{\frac{1}{\varrho-1}},
$$

is the average product quality interpreted as in Aghion and Howitt (or average productivity as in Melitz) and $L_{t}$ is labor allocated to the production of intermediary goods.

In the Schumpeterian model, an innovation is a new technology able to produce a better quality input, which is a perfect substitute of an already existing intermediary input (or a cheaper version of an intermediary input of the same quality). The particular input is randomly selected among the unit mass of existing intermediary inputs. When a new technology is discovered, the previous one becomes obsolete, making the previous producer to exit. ${ }^{30}$ Creation of new technologies is then associated with the destruction of old ones. The probability that a new version arrives follows a Poisson process with arrival rate $b$ for unit of labor allocated to $\mathrm{R} \& \mathrm{D}, b>0 .{ }^{31}$

The productivity of the new version is assumed to be equal to the frontier, leading-edge technology $\omega_{t}$, which given some $\omega_{0}>0$ at time $t=0$, is assumed to follow

$$
\frac{\dot{\omega}_{t}}{\omega_{t}}=b\left(1-L_{t}\right)
$$

where $1-L_{t}$ represents the share of total labor allocated to R\&D activities. ${ }^{32}$ Individual research effort spills over into the whole economy by

30 The distance in productivity between two consecutive innovations of a particular variety depends on the time interval between them. It may be that this distance is small enough to make the incumbent compete with the innovator. In this case, the innovation is said to be non-drastic. To avoid the associated complications of studying market structures with non-drastic innovations, it is assumed that the incumbent's technology is destroyed with the discovery of a new way of producing the same intermediary input.

${ }^{31}$ In this literature, an innovation is a random event. Let us denote by $F(T)$ the probability that this event occurs before a period of length $T$. A Poisson process assumes $F(T)=1-\mathrm{e}^{-\mu T}, \mu>0$. The associated density function is $f(T)=\mu \mathrm{e}^{-\mu T}$, implying that the probability that the event occurs around $T=0$ is $\mu$. The probability that the event does not occur before $T$ is $\mathrm{e}^{-\mu T}$.

32 Note that technology has a vintage structure. Innovations introduced at time $t$ have the frontier productivity $\omega_{t}$, which will be growing at equilibrium. 
moving the frontier of knowledge, mimicking a form of learning-bydoing.

Finally, let us assume that new varieties receive infinitely lived patents, giving to the innovator the exclusivity on the use of this technology to produce the corresponding intermediary input.

Let us denote by $a_{t}=\frac{z}{\omega_{t}}$ the productivity of $z$ relative to the frontier technology and by $H(a), a \in[0,1]$, the cumulative distribution of firms across technologies. It can be easily shown that at steady state the distribution $H(a)$ is uniform in $(0,1) .{ }^{33}$ It can also be shown that

$$
\bar{z}_{t}=\mu \omega_{t} \quad \text { with } \quad \mu=\varrho^{\frac{1}{1-\varrho}}<1 .
$$

The average technology $\bar{z}_{t}$ is at a distance $\mu$ from the frontier technology $\omega_{t}$. The distance to the frontier technology is increasing in $\varrho$, for $\varrho>1$, with $\lim _{\varrho \rightarrow \infty} \mu=1$, meaning that the average distance to the technological frontier approaches unity when intermediary inputs are close to perfect substitutes. On the other extreme, it goes to $e^{-1}$ when $\varrho$ goes to one.

At the balanced growth path, at any time $t$, the return to a patent aged $s$ is

$$
r=\underbrace{\frac{\pi_{s t}}{v_{s t}}}_{\text {dividend-to-value }}+\underbrace{\frac{\dot{v}_{s t}}{v_{s t}}}_{\text {capital gains }}-\underbrace{b(1-L)}_{\text {business-stealing }}-\underbrace{(\rho-1) b(1-L)}_{\text {obsolescence }} .
$$

As usual, the return to assets adds capital gains to the dividend-to-value ratio. The remaining terms represent the negative effect that technical progress has on the patent protecting existing intermediary inputs. The third term is the so-called business-stealing effect. It measures the Poisson rate at which the patent will eventually die, when the associated intermediary input is substituted by a subsequent innovation. The last term represents the obsolescence cost produced by the emergency of cheaper (better quality) versions of other intermediary inputs, reducing the demand for the input produced by the patent. ${ }^{34}$ As time passes, other varieties become more and more productive, reducing the demand and

33 The distribution of firms across relative productivities is uniform because, by assumption, the rate at which innovations arrive is the same as the rate at which the frontier technology grows. Otherwise, the distribution is Pareto, as it is usually assumed in this literature.

34 Aghion and Howitt (1992) refer to it as the crowding-out effect. 
profits of the variety we are evaluating. The obsolescence cost depends on the velocity at which the frontier technology moves, $b(1-L)$, and the elasticity of substitution across varieties. When varieties become perfect substitutes, old varieties are substituted out by new varieties fully, making the crowding-out effect infinity.

\subsubsection{Innovation and the Life Cycle of Firms}

Klette and Kortum (2004) extends the Melitz model in line with the literature on endogenous growth with the aim of describing better the life cycle of firms. In this framework, the productivity of firms does not depend on their own intrinsic characteristics, but it is randomly assigned. ${ }^{35}$

Firms and Products. In the Klette and Kortum (2004) framework, a continuum of firms produces a continuum of measure of one of intermediary inputs, with each firm producing an integer number $n_{t}$ of them, $n_{t} \in\{1,2,3, \ldots\}$. The integer number of intermediary inputs produced is heterogeneous and endogenously determined at equilibrium.

As in the Schumpeterian model, producing one unity of any intermediary input requires one unit of labor; labor productivity is normalized to one, and the same holds for all inputs. However, intermediary inputs are heterogeneous in their quality. The quality frontier of an intermediary input is denoted by $z_{t}$.

Innovation. Technical progress in each intermediary input is represented by a quality ladder model as in Grossman and Helpman (1991). The dynamics of the frontier technology for the different intermediary inputs is governed by two types of innovations: innovation by incumbent firms and innovation by potential entrants. When a discovery takes place, it is randomly assigned to a single intermediary input moving its quality frontier one step in the quality ladder. The gain in quality is given by a firm-specific factor $q>1$, which is specific to the firm that makes the discovery.

The firm-specific factor $q$ maps one-to-one to a firm-specific profit per intermediary input $\pi, \pi \in(0,1)$, and it is the same for all intermediary inputs produced by the same firm; $\pi$ and $q$ are positively related and time invariant. In the following, it is assumed that firms draw $\pi$ from

35 See also Acemoglu and Cao (2015). 
the continuous distribution function $\Phi(\pi)$, which is equivalent to draw factor $q$ from a known distribution. An operative intermediary firm is then characterized by a duple $\left\{n_{t}, \pi\right\}$, with $n_{t}$ evolving over time.

Innovation by Incumbents. A firm that exercises intensity $\lambda$, when undertaking $\mathrm{R} \& \mathrm{D}$ activities, has a Poisson rate $\lambda n$ of making a discovery, where $n$ is the number of intermediary inputs being currently produced by the firm. This discovery allows the firm to move one step in the quality ladder of the frontier technology of a randomly selected intermediary input. The particular input is unknown to the firm at the time the firm undertakes the $R \& D$ activities. The $R \& D$ cost function of a firm $\{n, \pi\}$ is

$$
\frac{\pi}{\bar{\pi}} c(\lambda) n \text {. }
$$

Function $c(\lambda)$ is increasing and strictly convex (some other technical assumptions s.t. $c(\lambda)>\lambda c^{\prime}(\lambda)$ are also required). The cost function depends on the firm-specific innovation factor $q$ through $\pi$; more innovative firms, those with larger $q$, face larger innovation costs. The optimal (interior) innovation policy requires

$$
\begin{gathered}
c^{\prime}(\lambda)=v \\
(r+\mu-\lambda) v=\bar{\pi}-c(\lambda),
\end{gathered}
$$

where $v$ represents the expected value of a product produced by a firm of average type $\bar{\pi}, r$ is the equilibrium interest rate and $\mu$ is the rate of creative destruction (measuring the rate at which the firm may lose a product line because another firm has just innovated in this particular product line). The first condition states that the marginal cost of innovation has to be equal to its marginal value. The second condition states that the expected return on innovation has to be equal to its opportunity cost. Irrespective of the firm-specific duple $\{n, \pi\}$, all firms optimally chose the same innovation intensity $\lambda$, the Poison rate of innovation of a firm with $n$ products being $\lambda n$. Indeed, more profitable firms face larger $\mathrm{R} \& \mathrm{D}$ costs and have larger per product value.

Innovation by Potential Entrants. There is a mass of potential entrants investing at the rate $F, F>0$, in return for a unit Poisson rate of entering the economy with a single product. Potential entrants, after entering, draw a firm-specific profit $\pi$ from $\Phi(\pi)$. The firm-specific profit 
$\pi$ and the associated innovation factor $q$ apply to the first and any subsequent discovery of the firm. As in the case of incumbents, a new entrant randomly chose an intermediary input.

Equilibrium Innovation. Notice first that at equilibrium $\mu=\lambda+\eta$, where $\eta$ is the Poisson rate of innovation by potential entrants. Free entry requires $F=v$, since in expected terms the potential entrant covers the entry cost $F$ with the value of the innovation. Combining the free entry condition and the optimal innovation policy of incumbents, the equilibrium innovation intensity of incumbents is determined by the condition

$$
c^{\prime}(\lambda)=F,
$$

and the equilibrium innovation intensity of potential entrants by

$$
\eta=\frac{\bar{\pi}-c(\lambda)}{F}-\rho
$$

where the interest rate $r=\rho$ at the balanced growth path.

These two equations are fundamental to understand the incentives to innovation in the Klette-Kortum model, and hence the potential effects of innovation policies. An increase in the entry cost $F$ reduces the R\&D activity of potential entrants $\eta$, but raises the incumbents' innovation intensity $\lambda$. An increase in average profits $\bar{\pi}$ raises the innovation intensity of new entrants but has no effect on incumbents. A raise in the innovation cost of incumbents (affecting both average and marginal costs) will have negative incentives for both incumbents and potential entrants. In this model, innovation policy affects innovation only through these channels, Of course, any policy that reduces the financial costs of firms, as reflected by $\rho$, also promotes innovation by potential entrants.

Limit Pricing. From the point of view of the final firm, the quality frontier version of any intermediary input is a perfect substitute of any previous version of the same input, with all versions weighted by their respective qualities. Under Bertrand competition, the firm producing the frontier quality optimally charges a markup $q$ to its marginal cost in order to deter any competitor. Consequently, at equilibrium only the frontier quality is produced with the last innovator charging a markup equal to its specific factor $q$. 
Intermediary inputs aggregate into the final output through the CobbDouglas technology

$$
y_{t}=\int_{z} \log (z x(z)) \phi(z) \mathrm{d} z,
$$

where $\phi(z)$ is the equilibrium distribution of the frontier quality across intermediary inputs. It is easy to see that the optimal demand implies $p(z) x(z)=1$. A firm with quality improvement factor $q$ yields then the same constant profit flow $\pi=1-q^{-1}, \pi \in(0,1)$, for each intermediary input it produces irrespective of its quality $z$, since $p(z) x(z)=1$ for all $z$.

\subsection{Further Contributions}

This survey does not review other important dimensions of the innovation process that may also be relevant for policy analysis, which should be considered when designing macro models for the evaluation of innovation policies.

First, there is a large literature analyzing the role of financial frictions shaping market selection and innovation. ${ }^{36}$ The evaluation of policies addressed to reduce financial frictions in order to promote innovation and productivity growth requires a rigorous modeling of the financial sector and the associated frictions.

Second, innovation policy needs also to be evaluated by its redistributive effects on the labor market, with regard to the correction of the negative effects that technical progress has in the evolution of employment and wages across industries and occupations. The recent literature on job polarization, automatization and skill obsolescence is addressed to study the labor market effects of innovation and technical progress. Technical progress develops differently in different sectors, affecting unevenly the dynamics of jobs and occupations. One of the most striking implications of these diverse sectorial evolutions of technology is stressed by the literature on structural transformation. ${ }^{37}$ This literature looks at replicating the evidence of non-balanced patterns of the three main

36 See Cooley and Quadrini (2001), Buera et al. (2011), and Midrigan and Yi Xu (2014), among others.

37 See Duarte and Restuccia (2010), as well as Herrendorf et al. (2014) for a survey on this literature. 
sectors of modern economies: agriculture, manufacturing and services. An appropriate modeling of this dimension, likely in line with Kongsamut et al. (2001), Ngai and Pissarides (2007), and Acemoglu and Guerrieri (2008), will be of great importance in order to evaluate industrial policies addressed to promote innovation.

The unbalanced evolution of industries is mimicked by an unbalanced evolution of occupations (see Duernecker \& Herrendorf, 2017), which is reflected in the polarization of wages and employment observed in the data (see Autor \& Dorn, 2013). Modeling the joint evolution of technology and occupations, in line with the skill obsolescence hypothesis in Licandro and Poschke (2017), is of fundamental importance to evaluate the labor market effect of innovation policies.

Third, trade, although omitted in this chapter, is fundamental to understand the impact of innovation policies. This is particularly important for the evaluation of innovation policies in the European Union, where policies are expected and frequently addressed to affect regions and countries differently (See Atkeson and Burstein [2010], Aw et al. [2011], Baldwin and Robert-Nicoud [2008], and Broda and Weinstein [2006], among others). A model of this nature is needed to evaluate the trade-off between promoting excellence, by addressing resources toward the most efficient regions, and regional convergence or catching-up.

\section{REFERENCES}

Acemoglu, D., \& Cao, D. V. (2015). Innovation by entrants and incumbents. Journal of Economic Theory, 157, 255-294.

Acemoglu, D., \& Guerrieri, V. (2008). Capital deepening and nonbalanced economic growth. Journal of Political Economy, 116(3), 467-498.

Adams, J. (1990). Fundamental stocks of knowledge and productivity growth. Journal of Political Economy, 98(4), 673-702.

Aghion, P., \& Howitt, P. (1992). A model of growth through creative destruction. Econometrica, 60, 323-351.

Akcigit, U., \& Kerr, W. R. (2017). Growth through heterogeneous innovations. Journal of Political Economy.

Arrow, K. (1962). The economic implications of learning-by-doing. Review of Economic Studies, 29(1), 155-173.

Atkeson, A., \& Burstein, A. T. (2008). Pricing-to-market, trade costs, and international relative prices. American Economic Review, 98(5), 1998-2031.

Atkeson, A., \& Burstein, A. T. (2010). Innovation, firm dynamics, and international trade. Journal of Political Economy, 118(3), 433-484. 
Autor, D. H., \& Dorn, D. (2013). The growth of low-skill service jobs and the polarization of the US labor market. American Economic Review, 103(5), 1553-1597.

Aw, B. Y., Roberts, M. J., \& Yi Xu, D. (2011). R\&D investment, exporting, and productivity dynamics. American Economic Review, 101(4), 1312-1344.

Baldwin, R., \& Robert-Nicoud, F. (2008). Trade and growth with heterogeneous firms. Journal of International Economics, 74(1), 21-34.

Bambi, M., Gozzi, F., \& Licandro, O. (2014). Endogenous growth and wave-like business fluctuations. Journal of Economic Theory, 154, 68-111.

Benassy, J.-P. (1996). Taste for intermediary input and optimum production patterns in monopolistic competition. Economics Letters, 52(1), 41-47.

Boucekkine, R., Del Rio, F., Licandro, O., \& Puch, L. (2005). Vintage capital and the dynamics of The AK model. Journal of Economic Theory, 120(1), 39-72.

Boucekkine, R., Germain, M., \& Licandro, O. (1997). Replacement echoes in the vintage capital growth model. Journal of Economic Theory, 74(2), 333348.

Broda, C., \& Weinstein, D. (2006). Globalization and the gains from variety. Quarterly Journal of Economics, 121(2), 541-585.

Buera, F., Kaboski, J., \& Shin, Y. (2011). Finance and development: A tale of two sectors. American Economic Review, 101(5), 1964-2002.

Collard, F., \& Licandro, O. (2018). The neoclassical model and the welfare cost of selection. Mimeo.

Comin, D., \& Hobijn, B. (2010). An exploration of technology diffusion. American Economic Review, 100(5), 2031-2059.

Comin, D., Hobijn, B., \& Rovito, E. (2008). Technology usage lags. Journal of Economic Growth, 13(4), 237-256.

Cooley, T., \& Quadrini, V. (2001). Financial markets and firm dynamics. American Economic Review, 91(5), 1286-1310.

Corrado, C., Hulten, C., \& Sichel, D. (2009). Intangible capital and US economic growth. Review of Income and Wealth, 3(55), 661-685.

Dixit, A. K., \& Stiglitz, J. E. (1977). Monopolistic competition and optimum product diversity. American Economic Review, 67(3), 297-308.

Duarte, M., \& Restuccia, D. (2010). The role of structural transformation in aggregate productivity. The Quarterly Journal of Economics, 125(1), 129-173.

Duernecker, G., \& Herrendorf, B. (2017). Structural transformation of occupation employment. mimeo.

Epifani, P., \& Gancia, G. (2011). Trade, markup heterogeneity and misallocations. Journal of International Economics, 83(1), 1-13.

Felbermayr, G., \& Licandro, O. (2005). The underestimated virtues of the twosector AK model. Contributions to Macroeconomics, The B: E. Journal. 
Gabler, A., \& Licandro, O. (1979).Endogenous growth through selection and imitation. European University Institute WP 2007/26.

Gilchrist, S., \& Williams, J. (2000). Putty-Clay and investment: A business cycle analysis. Journal of Political Economy, 108(5), 928-960.

Greenwood, J., Hercowitz, Z., \& Krusell, P. (1997). Long-run implications of investment-specific technological change. American Economic Review, 87, 342-362.

Grossman, G. M., \& Helpman, E. (1991). Quality ladders in the theory of growth. Review of Economic Studies, 68, 43-61.

Herrendorf, B., Rogerson, R., \& Valentinyi, A. (2014). Growth and structural transformation. Handbook of Economic Growth, 2, 855-941.

Hopenhayn, H. (1992). Entry, exit and frim dynamics in long run equilibrium. Econometrica, 70, 1127-1150.

Hopenhayn, H. (2014). Firms, misallocation, and aggregate productivity: A review. Annual Review of Economics, 6, 735-770.

Hsieh, C.-T., \& Klenow, P. (2009). Misallocation and manufacturing TFP in China and India. Quarterly Journal of Economics, 124(4), 1403-1448.

Impullitti, G., \& Licandro, O. (2018). Trade, firm selection, and innovation: The competition channel. Economic Journal, 128, 189-229.

Jovanovic, B. (1982). Selection and the evolution of industry. Econometrica, 50, $640-670$.

Jovanovic, B., \& Lach, S. (1997). Product innovation and the business cycle. International Economic Review, 38(1), 3-22.

Klette, T. J., \& Kortum, S. (2004). Innovating firms and aggregate innovation. Journal of Political Economy, 112(5), 986-1018.

Koeninger, W., \& Licandro, O. (2006). On the use of substitutability as a measure of competition. The B.E. Journal of Macroeconomics, 6(1).

Kongsamut, P., Rebelo, S., \& Xie, D. (2001). Beyond balanced growth. Review of Economic Studies, 68(4), 869-882.

Licandro, O. \& Poschke, M. (2017). Skill obsolescence. mimeo.

Lucas, R. (1978). On the size distribution of business firms. Bell Journal of Economics, 9(2), 508-523.

Luttmer, E. G. J. (2007). Selection and growth, and the size distribution of firms. Quarterly Journal of Economics, 122(3), 1103-1144.

Luttmer, E. G. J. (2011). On the mechanics of firm growth. Review of Economic Studies, 78(3), 1042-1068.

Luttmer, E. G. J. (2012). Technology diffusion and growth. Journal of Economic Theory, 147, 602-622.

Mansfield, E. (1989). The diffusion of industrial robots in Japan and the United States. Research Policy, 18, 183-192.

Melitz, M. (2003). The impact of trade on intra-Industry reallocations and aggregate industry productivity. Econometrica, 71, 1695-1725. 
Melitz, M., \& Redding, S. (2015). New trade models, new welfare implications. American Economic Review, 105(3), 1105-1146.

Midrigan, V., \& Yi Xu, D. (2014). Finance and misallocation: Evidence from plant-level data. American Economic Review, 104(2), 422-458.

Navas, A., \& Licandro, O. (2011). Trade liberalization, competition and growth. The B.E. Journal of Macroeconomics, $11(1)$.

Ngai, R., \& Pissarides, C. (2007). Structural change in a multisector model of growth. American Economic Review, 97(1), 429-443.

Peretto, P. (1996). Industrialization, technological change and long-run growth. Department of Economics, Working Papers 96-22.

Peretto, P. (2003). Endogenous market structure and the growth and welfare effects of economic integration. Journal of International Economics, 60(1), 177-201.

Rebelo, S. (1991). Long-run policy analysis and long-run growth. Journal of Political Economy, 99, 500-521.

Restuccia, D., \& Rogerson, R. (2017). The causes and costs of misallocation. Journal of Economic Perspectives, 31(3), 151-174.

Romer, P. M. (1990). Endogenous technological change. Journal of Political Economy, 98, 71-102.

Sampson, T. (2016). Dynamic selection: An idea flows theory of entry, trade, and growth. Quarterly Journal of Economics, 131(1), 315-380.

Solow, R. (1962). Substitution and fixed proportions in the theory of capital. Review of Economic Studies, 29, 207-218.

Solow, R., Tobin, J., Von Weizsacker, C., \& Yaari, M. (1966). Neoclassical growth with fixed factor proportions. Review of Economic Studies, 33, 79-115. 
Open Access This chapter is licensed under the terms of the Creative Commons Attribution 4.0 International License (http://creativecommons.org/licenses/ by $/ 4.0 /$ ), which permits use, sharing, adaptation, distribution and reproduction in any medium or format, as long as you give appropriate credit to the original author(s) and the source, provide a link to the Creative Commons license and indicate if changes were made.

The images or other third party material in this chapter are included in the chapter's Creative Commons license, unless indicated otherwise in a credit line to the material. If material is not included in the chapter's Creative Commons license and your intended use is not permitted by statutory regulation or exceeds the permitted use, you will need to obtain permission directly from the copyright holder.

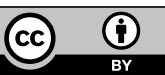

